This item was submitted to Loughborough's Research Repository by the author.

Items in Figshare are protected by copyright, with all rights reserved, unless otherwise indicated.

\title{
Plastic deformation and cracking resistance of SiC ceramics measured by indentation
}

PLEASE CITE THE PUBLISHED VERSION

http://dx.doi.org/10.1002/9781119031192.ch10

\section{PUBLISHER}

(c) The American Ceramic Society. Published by John Wiley \& Sons.

\section{VERSION}

AM (Accepted Manuscript)

\section{PUBLISHER STATEMENT}

This work is made available according to the conditions of the Creative Commons Attribution-NonCommercialNoDerivatives 4.0 International (CC BY-NC-ND 4.0) licence. Full details of this licence are available at: https://creativecommons.org/licenses/by-nc-nd/4.0/

\section{LICENCE}

CC BY-NC-ND 4.0

\section{REPOSITORY RECORD}

Wade, James, Phoebe Claydon, and Houzheng Wu. 2015. "Plastic Deformation and Cracking Resistance of Sic Ceramics Measured by Indentation”. figshare. https://hdl.handle.net/2134/18978. 


\section{PLASTIC DEFORMATION AND CRACKING RESISTANCE OF SIC CERAMICS MEASURED BY INDENTATION}

James Wade, Phoebe Claydon \& Houzheng Wu

Department of Materials, Loughborough University, Leicestershire, LE11 3TU, UK

\section{ABSTRACT}

Hardness is deemed as a measurement of resistance to plastic deformation of materials, but cracking, accompanying the deformation of ceramics, has recently been reasonably interpreted as one of the essential contributors to the widely known size effect of hardness, also called the indentation size effect. On the basis of the physical activities behind the indentation size effect, we intend to have the indentation size effect measurement adapted as a means to quantitatively measure the plastic deformation and the cracking damage of ceramics. We studied three types silicon carbide ceramics that were manufactured from same chemical formulation and processing route. Two of the three were given a post-sintering annealing at different dwell times, giving a distinctive microstructure from homogeneous equiaxial grains to highly heterogeneous elongated grains. By fitting the indentation size effect data with proportional specimen resistance model, the $a_{1}$ and $a_{2}$ parameters are extracted with good confidence. The $a_{2}$ value is interpreted as the "true hardness", the determined values of which were found to be similar for all samples. However, the $a_{l}$, relatable to the indentation size effect, increased dramatically together with the indentation-induced cracking around Vickers indents observed under SEM. Considering that the cracking resistances of all three samples showed limited variance, we discuss, using a simple illustrative model, the possible microstructural factors which may contribute to the cracking damage exhibited under a defined loading condition.

\section{INTRODUCTION}

Over recent years, sharp-contact indentation techniques (i.e. Vickers, Knoop, Berkovich, etc.) have been a convenient and universally accepted method to ascertain the mechanical property of hardness for a ceramic. Such a process involves penetrating the polished surface of a material with a loaded diamond indenter of a predetermined configuration. The hardness $(H)$ can then be substantiated as a ratio of the applied load $(P)$ to resultant contact area of the residual impression:

$$
H=\alpha \frac{P}{d^{2}}
$$

where $d$ is an average of the respective horizontal and vertical diameters for each indent in $\mu$ ms and $\alpha$ is a constant contingent on the indenter shape. This quantifiable value is frequently quoted by almost all researchers and engineers. However, the experimentally derived hardness is notorious for experiencing an apparent load-dependency, known as an indentation size effect (ISE), often resulting in the hardness decreasing with increasing load [1-3]. Consequently, values acquired by means of indentation, such as Vickers or Knoop, are, for the most part, superficial and hold no definitive significance. Thus, a multitude of attempts have been made to separate the load-dependent ISE from the load-independent hardness (also referred to as the "true hardness"), the expectation being that it may assist in identifying the physical mechanisms responsible for the ISE.

For brittle ceramics, Li and Bradt's proportional specimen resistance (PSR) model [4], given in eq. 2, which separates the ISE and hardness into $a_{1}$ and $a_{2}$ terms respectively, has been well-adopted: 


$$
P=a_{1} d+a_{2} d^{2}
$$

Here, the $a_{2}$ acts as a volumetric component, accounting for the geometric change that occurs as the indenter makes contact with the test material surface. Therefore, it is reasonably well-established that the $a_{2}$ denotes the resistance to crack-free plastic deformation and can be used to estimate the loadindependent hardness when no ISE is present (when $a_{l}=0$ ) and based on the indenter profile. Conversely, the $a_{1}$ term acts as a surface component and is believed to have some relation with surface energy, however the physical significance of this remains unknown.

One of the more convincing arguments is based on the premise that under external loading two competing mechanical responses dominate: plastic deformation and fracture. Given that the hardness and the $a_{2}$ can be attributed to the resistance to plastic deformation, Swain and Wittling suggested that the ISE phenomenon, and therefore the $a_{l}$, may be the result of subsurface cracking underneath the impression which facilitates deeper penetration of the indenter, lowering the measured hardness [5]. This was more recently supported by the work of Quinn and Quinn who expanded on the theory to include all cracks which form in, around and underneath the residual impression [6]. It is generally acknowledged that cracking in ceramics can be introduced during indentation and can happen in the very early stages of loading $[7,8]$. This is largely attributable to the fact that, at low temperatures, almost all polycrystalline ceramics have less than five independent slip systems that can be activated under normal loading circumstances to fully accommodate the required geometric changes [9]. Additionally, because of a relatively low cracking resistance, ceramics are unable to constrain any crack propagation from pre-existing flaws. Hence, unlike ductile metallic materials, hardness values directly estimated from eq. 1 provide information on the total performance of ceramics under external loading, rather than just lattice plastic deformation resistance, and include the cracking and densification, as well as external contributions such as interfacial friction between the indenter and the test material and environmental factors. Among these, friction, densification and the environment have been found to have negligible effect on the ISE [10]. Hence, it would seem somewhat prudent to presume that indentation-induced cracking is the primary cause of the ISE.

Herein, we propose a simple illustrative model depicting our understanding of how cracks may initiate and propagate during indentation. We intend to demonstrate how the ISE may provide information in regards to the cracking damage which can be quantified using the values of $a_{1}$. Experimental aspects of this study aim to improve our understanding how microstructural factors dictate cracking damage under contact loading conditions, the basis of which may allow ceramic microstructures to be tailored for specific engineering applications.

We selected silicon carbide $(\mathrm{SiC})$ ceramics for our study on the basis that a bimodal or heterogeneous microstructure can be achieved by applying a simple post-sintering annealing process at set dwell periods without altering the chemical composition and in turn the boundary chemistry. Meaning the fracture mode can remain largely the same or similar over relatively lengthy crack extensions, regardless of variations in grain size or morphology, which is necessary to limit changes in the overall fracture toughness of each sample.

\section{EXPERIMENTAL PROCEDURE}

A detailed methodology of sample fabrication, preparation and testing can be found elsewhere [11], but a brief description is provided below.

\section{Materials}


SiC tiles measuring $100 \mathrm{~mm}$ x $100 \mathrm{~mm} \times 8.5 \mathrm{~mm}$ were provided by Morgan AM\&T (Swansea, UK). All samples were die-pressed from the same starting powder and initially sintered in a vacuum furnace at $\sim 1900^{\circ} \mathrm{C}$. Differences in the grain morphology were subsequently achieved by performing a post-sintering heat treatment at $\sim 2000^{\circ} \mathrm{C}$ over varying dwell times. Generally, extended dwell times caused greater degrees of abnormal grain growth, resulting in sites of grain elongation and coarsening. As-received samples included; one which was not subjected to any post-sintering heat treatment, herein coded as U-SiC because of its unimodal microstructure, one which was heat treated for a short period, herein coded as $\mathrm{B}-\mathrm{SiC}$ because of its bimodal microstructure, and one that was heat treated for a long period, herein coded as $\mathrm{H}-\mathrm{SiC}$ because of its heterogeneous microstructure.

\section{Sample Preparation}

In order to test the samples, small pieces of each were cut away using a diamond tile saw. An assortment of these smaller sample sections were then directly used to perform density measurements using the Archimedes method. The rest were mounted onto a mild steel block using a hard wax and ground/polished to a $1 \mu \mathrm{m}$ surface finish. Although the majority of the polished samples were used for hardness testing, a few were chemically etched to expose the microstructures which were subsequently imaged under a Reichert-Jung MEF3 optical microscope (Reichert Technologies, USA).

\section{Grain Size and Aspect Ratio Measurements}

Measurements of grain size were achieved by superimposing a uniform grid over SEM images of etched microstructures and determining the intercept length, defined as the distance between two points at which the grain boundary intersected the grid. For each sample, this was performed on 5 different SEM images that were previously taken in a Carl Zeiss (Leo) $1530 \mathrm{VP}$ scanning electron microscope (Carl Zeiss, Cambridge, UK). Depending on the degree of grain size heterogeneity, such intercept length measurements may have been done over a series of magnifications.

Aspect ratios were estimated by dividing the manually measured maximum length of a grain by the manually measured maximum width. For statistical reliability, this was done over $300 \times$ across multiple SEM images.

\section{Vickers Indentation}

Vickers indentation tests were performed using two indenters; a Mitutoyo HM-124 (Mitutoyo UK Ltd, Andover, UK) at loads of 0.05-2kgf (0.49-19.61N) and an Innovatest Nexus 4503 (Innovatest Europe, Maastricht, The Netherlands) for higher loads of $2.5-10 \mathrm{kgf}(24.51-98.07 \mathrm{~N})$. Tests were performed with an elected dwell time of 15 seconds and at room temperature. A minimum of 5 indents of a satisfactory condition were generated at each load. These indents were then imaged in the SEM and measured using a graphic editing program (Adobe Photoshop, USA). The Vickers hardness was then calculated in accordance with eq. 1 , where $\alpha$, the indenter specific constant $=1.8544$ for a Vickers indenter and the load, $P$, was in Newtons.

\section{EXPERIMENTAL RESULTS}

\section{Microstructural Heterogeneity}

Figure 1(a, b and c) displays the microstructures of each SiC sample after chemical etching. By comparatively assessing each image, it is apparent that the supplementary post-sintering heat treatment has induced abnormal grain growth, the degrees of which are contingent on the length of the selected 
dwell period over which samples are held at a high temperature. This has resulted in a transformation from the fine, equaxial grains of a unimodal or homogeneous grain structure (U-SiC), to a two-tier microstructure composed of a few elongated grains surrounded by fine grains, usually described as bimodal (B-SiC), to a coarser, highly-elongated structure, most commonly referred to as heterogeneous (H-SiC).
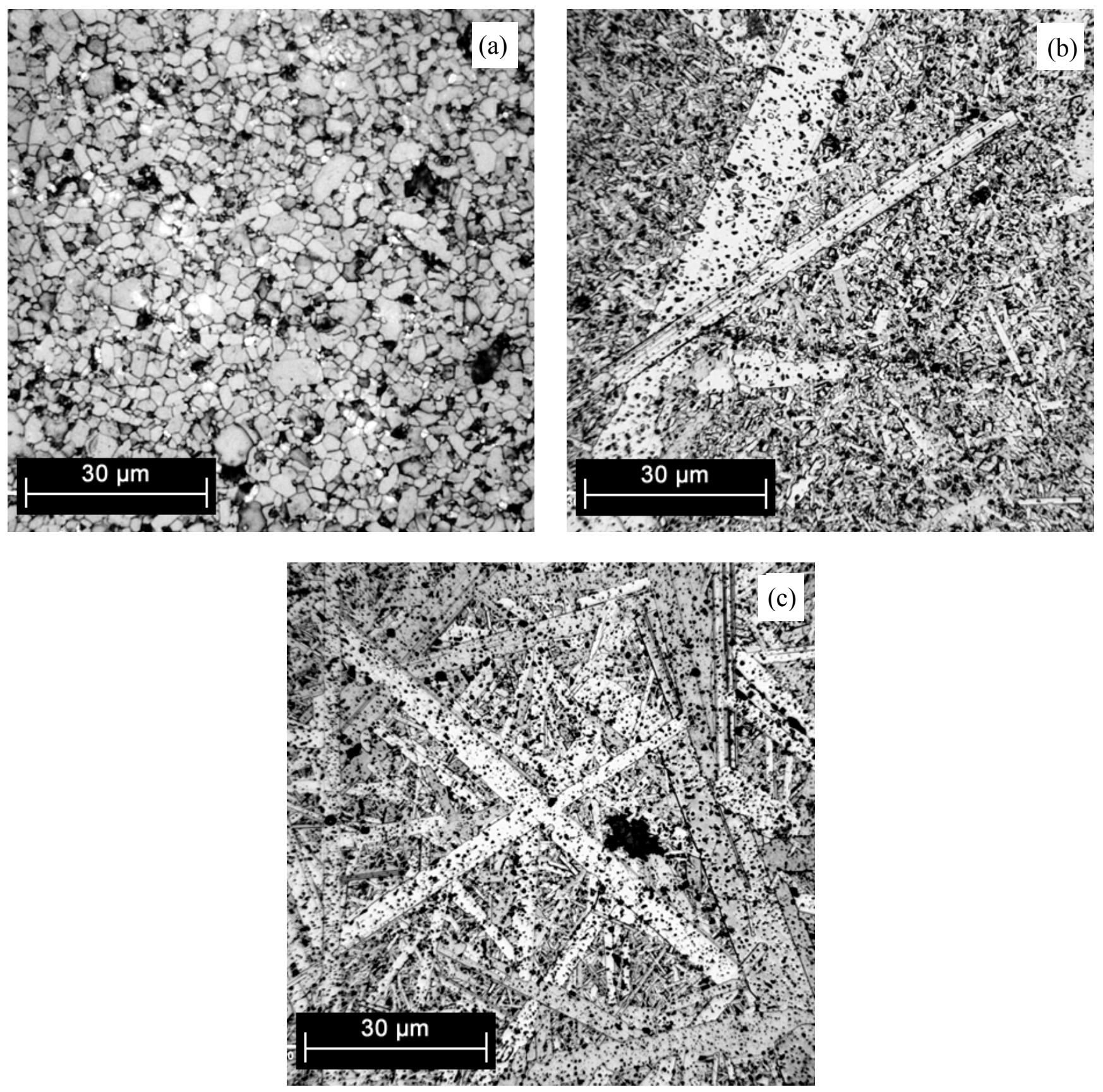

Fig. 1: Optical microscopy images of the resolved microstructures of as-received SiC samples after $1 \mu \mathrm{m}$ polishing and chemical etching: (a) $\mathrm{U}-\mathrm{SiC}$ is an equiaxed, fine grain structure (b) $\mathrm{B}-\mathrm{SiC}$ is an equiaxed grain structure with a few elongated grains evenly distributed throughout (c) $\mathrm{H}-\mathrm{SiC}$ is a coarse, elongated or plate-shaped grain structure. 
By using the measured aspect ratios in conjunction with the intercept lengths the degree of heterogeneity in each sample can be quantified. As expected, U-SiC has the lowest aspect ratio of around $1.44 \pm 0.38, \mathrm{~B}-\mathrm{SiC}$ has mid-range value of $3.50 \pm 1.41$, and $\mathrm{H}-\mathrm{SiC}$ has the largest aspect ratio of 9.35 \pm 4.62. Similarly, a comparable trend is exhibited by the intercept length distributions, which are $0.15-7 \mu \mathrm{m}$ for $\mathrm{U}-\mathrm{SiC}, 1-135 \mu \mathrm{m}$ for $\mathrm{B}-\mathrm{SiC}$, and $2-400 \mu \mathrm{m}$ for $\mathrm{H}-\mathrm{SiC}$. This indicates that a discernible change in grain scale occurs concurrently with grain elongation during post-sintering annealing.

An additional feature that was particularly noticeable was the surface pores. The densities of each sample were measured to be $\sim 3.02 \mathrm{~g} / \mathrm{cm}^{3}$ for $\mathrm{U}-\mathrm{SiC}, \sim 3.05 \mathrm{~g} / \mathrm{cm}^{3}$ for B-SiC, and $\sim 3.08 \mathrm{~g} / \mathrm{cm}^{3}$ for $\mathrm{H}$ $\mathrm{SiC}$, equating to theoretical densities of $94 \%, 95 \%$ and $96 \%$ and calculated porosity levels of $5.91 \%$, $4.98 \%$ and $4.05 \%$ respectively. Whilst the shape of the pores across all three samples appeared to be near-spherical, the size and density varied dramatically. For U-SiC, the pores tended to be very small, but in high densities. By contrast, the pores in H-SiC were significantly larger, but there were far fewer of them.

\section{Vickers Indentation and the Indentation Size Effect}

The results of Vickers indentation tests are listed in Table 1 together with the corresponding standard deviation for each measurement. This data is also depicted as a set of hardness-load curves in Fig. 2. Qualitative analysis of such plots highlights a notable decrease in the measured Vickers hardness $(H V)$ over an increasing load-regime of $0.05-20 \mathrm{~N}$, confirming that each sample suffers from a distinct ISE. Beyond this point, from $20-40 \mathrm{~N}$, the $H V$ begins to plateau, signifying that the ISE is no longer present. The values for $H V$ over this equalised region reveal that $\mathrm{U}-\mathrm{SiC}$ and $\mathrm{B}-\mathrm{SiC}$ coincide well with one another at $\sim 23 \mathrm{GPa}$, whereas $\mathrm{H}-\mathrm{SiC}$ is approximately $1 \mathrm{GPa}$ lower in value at $\sim 22 \mathrm{GPa}$.

Note, for B-SiC, an unforeseen and abrupt decline in $H V$ is observed at the lowest load of $0.49 \mathrm{~N}$. The reason surrounding the appearance of such an anomaly remains unclear. However, the peculiar behaviour of the reading means it has been ignored in the following model fittings.

Table 1: Vickers hardness values at loads of $0.49-39.23 \mathrm{~N}$ accompanied by uncertainties of one standard deviation.

\begin{tabular}{cccc}
\hline Load $(\mathbf{N})$ & U-SiC $H \boldsymbol{V}(\mathbf{G P a})$ & B-SiC $\boldsymbol{H}(\mathbf{G P a})$ & H-SiC $\boldsymbol{H}(\mathbf{G P a})$ \\
\hline $\mathbf{0 . 4 9}$ & $28.34 \pm 0.8$ & $26.49 \pm 1.0$ & $28.97 \pm 1.4$ \\
$\mathbf{0 . 9 8}$ & $26.83 \pm 0.8$ & $27.72 \pm 1.2$ & $27.34 \pm 0.5$ \\
$\mathbf{1 . 9 6}$ & $26.05 \pm 0.8$ & $27.15 \pm 0.8$ & $26.72 \pm 0.5$ \\
$\mathbf{2 . 9 4}$ & $25.31 \pm 0.5$ & $26.60 \pm 1.0$ & $26.22 \pm 1.6$ \\
$\mathbf{4 . 9 0}$ & $24.14 \pm 2.4$ & $25.65 \pm 0.9$ & $24.74 \pm 1.2$ \\
$\mathbf{9 . 8 1}$ & $24.02 \pm 1.0$ & $24.13 \pm 0.6$ & $23.93 \pm 0.9$ \\
$\mathbf{1 9 . 6 1}$ & $23.44 \pm 1.5$ & $23.11 \pm 0.6$ & $22.95 \pm 0.6$ \\
$\mathbf{2 4 . 5 1}$ & $22.71 \pm 0.5$ & $23.04 \pm 0.1$ & $22.02 \pm 0.8$ \\
$\mathbf{2 9 . 4 2}$ & $22.80 \pm 0.2$ & $23.07 \pm 0.3$ & $21.87 \pm 0.6$ \\
$\mathbf{3 9 . 2 3}$ & $22.99 \pm 0.3$ & $22.63 \pm 0.9$ & $21.96 \pm 1.1$ \\
\hline
\end{tabular}




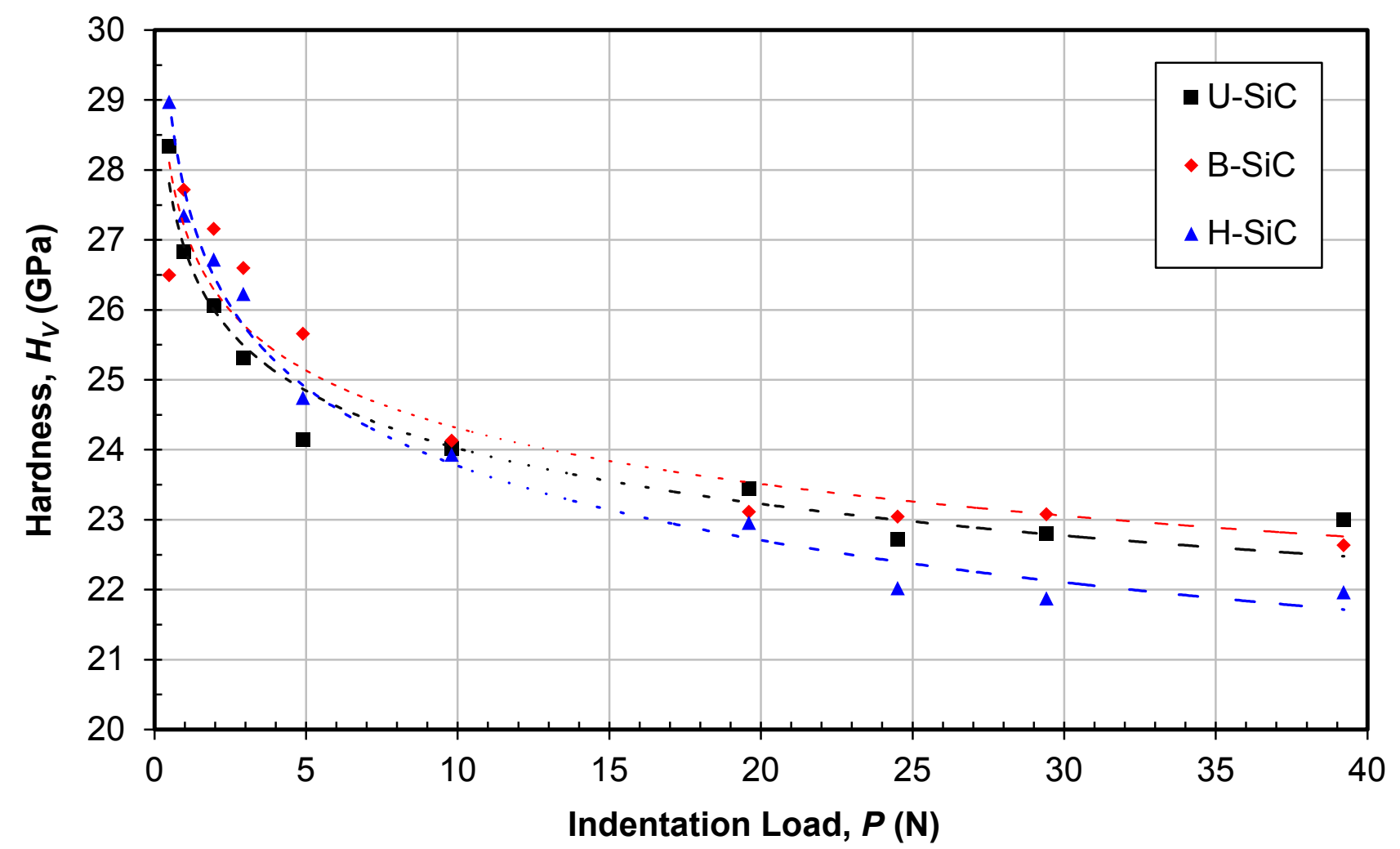

Fig. 2: The variation in Vickers hardness as a function of indentation load for U-SiC, B-SiC and H-SiC with power trendlines highlighting the ISE.

By adopting Meyer's Law, we can quantitatively estimate the severity of each ISE. If the exponent, $n$, is equal to 2 then no ISE is present, however any value $<2$ acts an inverse indicator of the ISE severity. From the $n$ values listed in Table 2, it is possible to confirm that all samples experience an ISE of varying degrees. U-SiC, with an $n$ value closest to 2, suffers the least from an ISE, whereas $\mathrm{H}-\mathrm{SiC}$, with the lowest $n$ value, possesses the greatest ISE.

Table 2: A summary of the $n$ and $A$ parameters determined using the Meyer's Law together with the $a_{1}, a_{2}$ terms according to the PSR model and "true hardness" values.

\begin{tabular}{ccccccc}
\hline \multirow{2}{*}{ Materials } & \multicolumn{2}{c}{ Meyer's Law } & & \multicolumn{3}{c}{ Proportional specimen resistance model } \\
\cline { 2 - 3 } \cline { 5 - 6 } & $n$ & $A$ & & $a_{1}(\mathrm{~N} / \mathrm{mm})$ & $a_{2}\left(\mathrm{~N} / \mathrm{mm}^{2}\right)$ & $H_{P S R}(\mathrm{GPa})$ \\
\hline U-SiC & 1.907 & 52.85 & & $22.09 \pm 7.3$ & $11918.14 \pm 157$ & 22.96 \\
B-SiC & 1.887 & 51.55 & & $40.22 .16 \pm 4.5$ & $11510.16 \pm 97$ & 22.90 \\
H-SiC & 1.876 & 50.16 & & $46.81 \pm 8.2$ & $10952.05 \pm 173$ & 22.08 \\
\hline
\end{tabular}

The PSR model fittings, also presented in Table 2, separate the curves in Fig. 2 into the $a_{1}$ and $a_{2}$ terms. From the estimated values it is evident that the $a_{2}$, acknowledged to be related with the resistance to plastic deformation and the load-independent hardness $\left(\mathrm{H}_{\mathrm{PSR}}\right)$, show a limited variance of $0.88 \mathrm{GPa}$ across the three samples, an improvement of only $3.83 \%$. The $a_{1}$, on the other hand, exhibits a substantial increase of $111.91 \%$ through U-SiC to H-SiC which implies that the $a_{1}$ holds greater significance to the total performance of the SiC ceramics during Vickers indentation. 


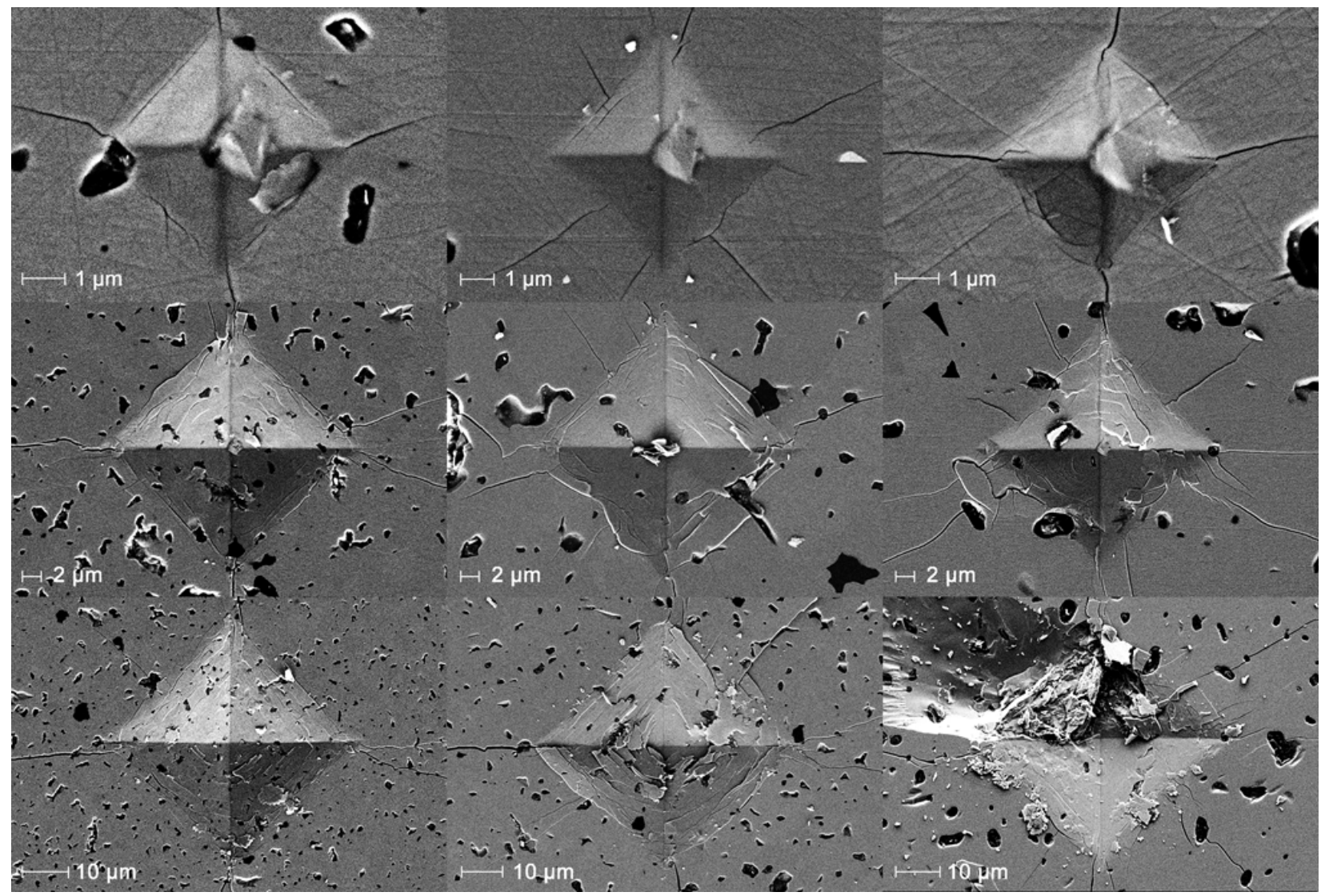

Fig 3: Selected indents made on $\mathrm{U}-\mathrm{SiC}(\mathrm{a}, \mathrm{d}, \mathrm{g}), \mathrm{B}-\mathrm{SiC}(\mathrm{b}, \mathrm{e}, \mathrm{h})$ and $\mathrm{H}-\mathrm{SiC}(\mathrm{c}, \mathrm{f}, \mathrm{i})$ at the following loads: (a, b, c) $0.49 \mathrm{~N},(\mathrm{~d}, \mathrm{e}, \mathrm{f}) 9.81 \mathrm{~N},(\mathrm{~g}, \mathrm{~h}, \mathrm{i}) 39.23 \mathrm{~N}$.

During Vickers indentation tests, cracking occurred readily in all three samples. Figure 3(a-i) demonstrates how all three samples, under an increasing load, show a diverging shift in the total amount of cracking within the plastic/elastic region inside and around the residual indent. For example, at the lowest load of $0.49 \mathrm{~N}$ (Fig. 3a, b and c), indents made on U-SiC, B-SiC and H-SiC bear close resemblance, with cracks that run parallel with the indent edges as well as radial cracks being wellformed and easily distinguishable in all samples. However, at a heavier load of 9.81N (Fig. 3d, e and f), cracks within the indents themselves became increasingly more common and each sample displayed a consecutive increase in the number of radial cracks which formed around the indents. In addition, cracking that propagated inside indents generated on $\mathrm{B}-\mathrm{SiC}$ and $\mathrm{H}-\mathrm{SiC}$ was far more damaging compared to U-SiC. At the highest load of 39.23N (Fig. 3g, h and i), despite such indents not being of an acceptable standard for measurement, H-SiC could be defined by an appreciable upsurge in the frequency of indent failure via severe chipping. Conversely, at the same load, this issue was slightly less prevalent in indents made on $\mathrm{B}-\mathrm{SiC}$ and a problem that rarely occurred in U-SiC. It is worth noting that Wilantewicz et al. documents similar incidences in three types of $\mathrm{SiC}$ and similarly notes that cracking was more severe in samples with a higher $a_{1}$ and a lower hardness [12].

\section{DISCUSSION}

As mentioned previously, the analysis of Swain and Wittling and of Quinn and Quinn deduced that the $a_{1}$ is attributable to the effects imposed by the ISE and that the ISE is caused by the cracking 
that occurs during indentation, therefore, larger $a_{1}$ values should indicate proportionally greater cracking.

The present findings appear to be consistent with such a statement, demonstrating how three $\mathrm{SiC}$ ceramics composed from the exact same starting powder, but with a modified grain structure, can have, all in ascending order of microstructural heterogeneity, an increase in the quantified ISE, an increase the $a_{1}$ values, and an increase in the amount of indentation-induced cracking. This exhibition of such drastically different behaviour during straightforward indentation experiments over a variable load-regime means that one or more microstructural factors must have altered each samples mechanical response to indentation. Appropriately, in order to fully understand how or what could be contributing to the aforementioned increase in the ISE, the $a_{1}$ and the indentation-induced cracking, we first provide a simple model of the indentation process whilst systematically addressing influential properties of significance. To simplify the analysis, a conical sharp indenter is considered instead of the pyramidal Vickers indenter used. This is to avoid the possible complications introduced by the corners, as adapted by other researchers [13].

As a first approximation, we follow Yoffe's approach to resolve the stress configuration in the $\mathrm{SiC}$ ceramics directly underneath and around the indenter during indentation [13]. Here, under an elastic/plastic deformation condition, a plastic zone is produced and restricted to an area directly beneath the contact interface of the indenter and the ceramic surface. As shown in Fig. 4, this hemispherical region of plastically deformed material is equal to a pressurised "blister" of uniform compression with a radius, $a$, equal to, $d$, the radius of the indentation impression. Appropriately, the $a_{2}$ term is associated with the density of dislocations which generate within the plastic zone during loading.

Beyond this yield region, a tensile elastic stress field, following that of Boussinesq solution for a point load, $P$, develops. According to Yoffe's analysis, the elastic field, which is also hemispheric in form, is subject to tensile stresses in the radial direction, $r$, the angle between the loading axis and the radial direction, $\theta$, and the circumferential angle about the indentation direction, $\varphi$. Under this scenario, the maximum tensile stress is along the circumferential direction and exists at the plastic/elastic boundary, rapidly degrading outwards away from the plastic zone.

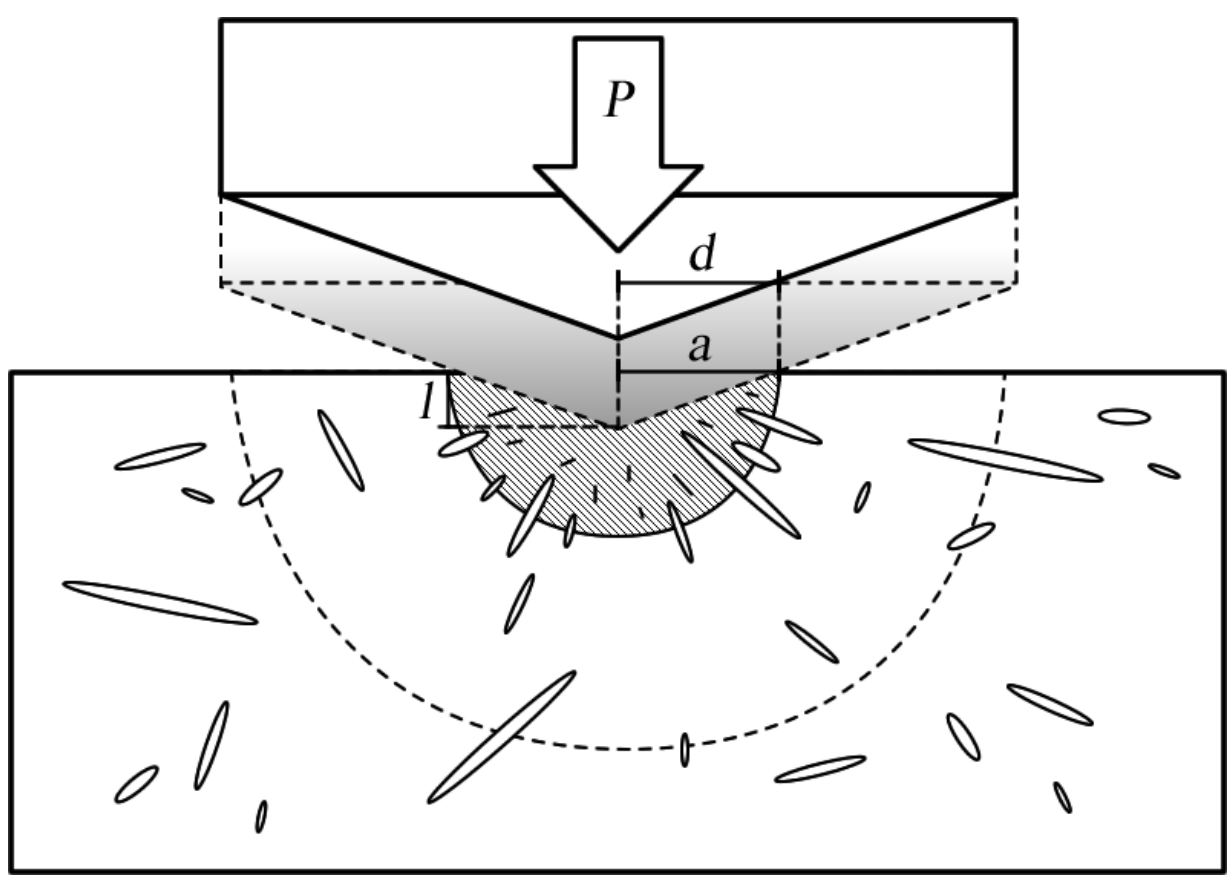

Fig. 4: A 2D schematic depicting the stressing condition underneath the indenter. 
Given that the depth of penetration, $l$, is proportional to $d$, and that $d=a$, as the indenter penetrates deeper into the surface of the $\mathrm{SiC}$ ceramics, the plastic/elastic boundary expands, searching for pre-existing flaws to activate. This activation involves a stage of crack initiation, followed by shortor long-crack propagation, both of which are governed by the fracture toughness, the tensile stress configuration, and the size of pre-existing flaws. In another investigation [11], we demonstrated, using Hertzian indentation, that the critical stress intensity factor $\left(K_{I C}\right)$ of the $\mathrm{SiC}$ ceramic samples used in this study is close enough to be of negligible influence. Furthermore, we assume that the stress conditions experienced by both $\mathrm{SiC}$ ceramics are interchangeable considering the concurrent nature of each samples mechanical properties. Therefore, it may be inferred that the pre-existing flaw size is primarily responsible for the crack formations in the three SiC ceramics.

Under the principle rules of linear fracture mechanics, cracking initiation and propagation from a flaw is dependent on the stress intensity factor $(K)$ at the tip. When the $K$ is larger than the $K_{I C}$, cracking commences and continuous to propagate until $K$ declines to a level below the $K_{I C}$. Smaller flaws have a lower $K$ that either does not exceed the $K_{I C}$ necessary to trigger cracking or that does trigger cracking, but where the $K$ is not high enough to escape the continual progression of the plastic/elastic boundary and is eventually consumed inside the yield region under compression. Larger flaws, however, have a much higher $K$, large enough for crack propagation to extend well into the elastic region even when part of the crack is included inside the yield zone. These long cracks are what we see in Fig. 3. However, this is not to say that short-cracks consumed by the plastic zone have no bearing on the $a_{1}$ values.

Based on this previous analysis, it is possible that a high density of larger flaws could facilitate greater cracking damage by providing a greater number of flaws at which the $K$ is significantly high enough to surpass the $K_{I C}$. The intrinsic flaw populations are defined by the microstructure of the asmanufactured samples and include pores, voids or progressing cracks. It has been noted, from the microstructures in Fig. 1, that porosity, in particular the shape and size of pores, varied significantly across the three samples, with U-SiC exhibiting the smallest pores and $\mathrm{H}-\mathrm{SiC}$ the largest pores, despite the total amount of porosity declining from $\mathrm{U}-\mathrm{SiC}$ to $\mathrm{H}-\mathrm{SiC}$. This is supported by Fig. 3, were pore size also increases from U-SiC to $\mathrm{H}-\mathrm{SiC}$.

\section{CONCLUSION}

Vickers hardness-load plots revealed that all three SiC samples, exhibiting increasing degrees of microstructural heterogeneity, suffer from a distinct ISE. By fitting such data into the PSR model, we were able to separate the ISE and the "true hardness" into the $a_{1}$ and $a_{2}$ terms respectively. In all three samples, the "true hardness" values were found to be highly comparable, whereas the $a_{1}$ values more than doubled from U-SiC to H-SiC. As anticipated, the amount of cracking around the indentation sites correlated well with increases in the $a_{1}, \mathrm{H}-\mathrm{SiC}$ displaying the most cracking damage and $\mathrm{U}-\mathrm{SiC}$ the least.

Based on our analysis, the stress condition experienced by all three SiC samples is the same. In addition, all three $\mathrm{SiC}$ samples share approximately identical properties of hardness, fracture toughness and Young's modulus. Thus, we deduce that increases in the cracking damage in, around and underneath the indentation impression must be attributable to the flaw population. In regards to the microstructure, we speculate that, despite the total calculated porosity decreasing from U-SiC to $\mathrm{H}-\mathrm{SiC}$, the flaw population is heavily influenced by the size of individual pores inherent within the asmanufactured samples which seem to coalesce with extended dwell-times during the post-sintering annealing process. 


\section{REFERENCES}

[1] Bernhardt E. Über die mikrohärte der feststoffe im grenzbereich des Kick'schen. Ähnlichkeitssatzes. Z Metallkd 1941; 33: 135.

[2] Frohlich F, Grau P, Grellmann W. Performance and analysis of recording microhardness tests. Phys Status Solidi A 1977; 42: 79-89.

[3] Sargent PM, Page TF. Influence of microstructure and microhardness of ceramic materials. $\mathrm{Pro} \mathrm{Br}$ Ceram Soc 1978; 26: 209-34.

[4] Li H, Bradt R. The indentation load/size effect and the measurement of the hardness of vitreous silica. J Non-Cryst Solids 1992; 146: 197-212.

[5] Swain M, Wittling M. Indentation size effect for brittle materials: Is there a simple fracture mechanics explanation, in: Bradt RC, Hasselman DPH, Munz D, Sakai M, Shevchenko VY (Eds.) Fracture Mechanics of Ceramics. Vol. 11. New York: Plenum Press; 1996.

[6] Quinn JB, Quinn GD. Indentation brittleness of ceramics: a fresh approach. J Mater Sci 1997; 32: 4331-46.

[7] Li H, Bradt RC. The effect of indentation-induced cracking on the apparent microhardness. J Mater Sci 1996; 31: 1065-70.

[8] Quinn G, Green P, Xu K. Cracking and the indentation size effect for Knoop hardness of glasses. $J$ Am Ceram Soc 2003; 86: 441-48.

[9] Groves GW, Kelly A. Independent slip systems in crystals. Philos Mag 1963; 8: 877-887.

[10] Hirao K, Tomozawa M. Microhardness of $\mathrm{SiO}_{2}$ glass in various environments. J Am Ceram Soc 1987; 70: 497-502.

[11] Wade J, Ghosh S, Claydon P, Wu H. The cracking-resistance of silicon carbide ceramics with a heterogeneous grain structure. Submitted.

[12] Wilantewicz T, Cannon WR, Quinn G. The indentation size effect (ISE) for Knoop hardness in five ceramic materials. Am Ceram Soc Proc 2013; 27: 237-50.

[13] Yoffe EH. Elastic stress fields caused by indenting brittle materials. Philos Mag A 1982; 46: $617-$ 628. 